RESEARCH REPORT

\title{
Socioeconomic differences in children's use of physician services in the Nordic countries
}

\author{
M Halldórsson, A E Kunst, L Köhler, J P Mackenbach
}

J Epidemiol Community Health 2002;56:200-204

\begin{abstract}
Objective: To assess the relation between socioeconomic factors and the use of physician services among children and whether variations of the level of co-payment are correlated with different levels of inequalities in health services use.

Design: Description of the socioeconomic differences in the use of health care using data from countrywide postal surveys to parents.

Setting: The five Nordic countries in 1996.

Subjects: Samples of 15000 children aged 2-17 years: 3000 children at random, from the national registry in each country.

Main outcome measure: Odds ratios of use of GP, specialist, and hospital services between children according to the educational level of both parents and the disposable income of the family, for all countries together and for each country separately. Odds ratios were adjusted for age, sex, urbanisation grade, and health status. Results: There was little difference in the use of GP services according to socioeconomic factors. Parents from lower socioeconomic groups used telephone services of physicians less than parents from the higher groups and children of lower socioeconomic groups were seen less often by specialists. The reverse was true for hospitalisation of the children. The differential use of those three types of services was more marked in Denmark, Finland and Norway than in Iceland and Sweden. When controlled for other socioeconomic factors, the largest differences were observed according to the education of the mother.

Conclusion: The specialist services and use of telephone services for children in the Nordic countries do not meet the criteria of equal use for equal need whereas the GP services and hospital services do to some extent. The education of the mother is a more important determinant than income for the use of each service.
\end{abstract}

See end of article for authors' affiliations

Correspondence to:

Dr M Halldórsson,

Bollagardar 3, 170

Seltjarnarnes, Iceland;

matthias@landlaeknir.is

Accepted for publication 24 July 2001

E quity is one of the main objectives of publicly organised health services. The most common definition of equity is "equal use for equal need". Equity exists when the services are distributed on the basis of need rather than as a result of structural or individual factors such as income, education, occupation or place of living. Most studies show that in countries with universal coverage of services and low or no co-payment at the point of use, the lower social classes tend to use the health services more than the better off, whether the system is a national health service, as in Britain, ${ }^{12}$ Spain $^{3}$ and Sweden, ${ }^{4}$ or an insurance based system as in the Netherlands. ${ }^{5}$ New research from Britain suggests that services for children and young people aged 1-19 are provided equitably when corrected for need. ${ }^{6}$ In the United States with a system of private insurance, where 40 million people are uninsured, the reverse is true: people in the lower classes use all services to a lesser degree. This has been found both for adults and for children. ${ }^{78}$ Studies from Canada ${ }^{9}$ show that the introduction of universal health services without co-payment resulted in an inverse association between income and use of health care.

The health services in the Nordic countries can be described as tax financed, universal, and comprehensive. Payment at the point of use can be regarded as small in most of the countries and for children usually a reduced amount is paid. But even a small payment might lead to underuse of the services by the poor. ${ }^{10}$ There may also be other barriers than payment: it is well known that the distance the patient has to travel to see the doctor can act as a barrier. Besides obvious geographical factors it is not clear whether physician services for children in the Nordic countries are used equitably. People from the lower classes may not be as effective as the better off in expressing their need because of language barriers or lack of communication skills. This article attempts to answer the question whether there is a differential use of curative health services for children in the Nordic countries according to socioeconomic status (SES). As there are some structural differences in the health services between the Nordic countries, especially with regard to levels of co-payment, we will also determine whether use is provided more equitably in some of the countries than in others.

\section{METHODS}

In March 1996 questionnaires were mailed to the parents of 15255 children aged 2 to 17 (around 3000 in each country), who were randomly selected from the national population registries. Two reminders were sent to non-responders, except in Norway where only one remainder was permitted. The questionnaire was translated from Swedish into Danish, Finnish, Icelandic and Norwegian and backtranslated by bilingual persons.

The study design and the response rate have been described in detail elsewhere. ${ }^{11}$ The response rate was highest in Finland $(79.5 \%)$, about $69 \%$ in Denmark, Sweden and Iceland, and lowest in Norway (64.5\%). Non-response analysis was done to a different degree in the five countries. In most cases it was done by the statistical bureaus in each country. There was hardly any difference in response rate according to the sex of the child in any of the countries and little difference between age categories. Families with low education, working class and 
one parent families were over-represented among nonresponders. Little difference was found according to urbanisation grade. In the country with the largest non-response rate, Norway, the largest difference in response rate was for education of the mother, with $80 \%$ response rate in the highest educational category but only $50 \%$ in the lowest category. This difference according to education was much smaller in Sweden, for example.

Use of health care was measured by asking whether the parents had consulted a general practitioner (GP), a specialist or had a phone call to any doctor for their children during the previous three months, and whether the child had been admitted to a hospital during the previous year. Visits for health check ups were not included.

Indicators of SES used in this study were the educational levels of the father and the mother, and the family income. Educational level was measured as the highest level of completed education. Four levels were distinguished: university/college level, upper secondary school education ( $>12$ years), lower secondary school education (10-12 years) and primary school only ( $<10$ years). Family income was measured as the disposable monthly income of the family. It comprised salary, pension, income from own firm and benefits and allowances (for example, child benefits, maintenance benefits, housing benefits, and social benefits). Income was measured as a continuous variable. In each country it was divided into four categories, from the highest to the lowest, with roughly equal number of children in each group.

Three models were used to analyse the association between socioeconomic variables and each kind of health service used. Model I adjusted for age (three-year age groups), sex and urbanisation grade. Urbanisation grade was measured as living in a town of more than 100000 inhabitants, a town or village with a population between 3000 and 100 inhabitants, or living in a rural place with population less than 3000 inhabitants.

Model II additionally adjusted for health status in order to take into account socioeconomic differences in need for health services. Two health indicators were used: having at least one chronic condition, and experiencing at least one moderate or severe symptom at least every other week. The list of chronic conditions included diabetes, visual impairment, hearing impairment, speech defect, psychiatric disorder, epilepsy, gastric disorder, asthma, allergies, eczema, physical disablement, overweight, and hyperactivity. The symptoms included were

\section{Key points}

- There are small socioeconomic differences in the use of GP services by children in the Nordic countries.

- Children of parents in disadvantaged socioeconomic groups used specialist services and phone calls to doctors to a lesser degree than did the better off.

- There are differences in the co-payment for children in the five Nordic countries, from no co-payment to a considerable co-payment. The comparison between countries did not show a relation between levels of co-payment and differential use of physician services between income groups.

- Low education of parents, especially the mother, is a more important determinant of health care utilisation for children than the financial situation of the families in the Nordic countries.

stomach pain, headache, back pain, disorders of sleep, dizziness, and loss of appetite. The lists of chronic diseases and symptoms were compiled by experienced paediatricians in the Nordic countries, but they have not been tested for validity or reliability.

In model III we additionally adjusted each socioeconomic factor used in these tables for all other socioeconomic factors, in order to determine the independent contribution of this factor to the socioeconomic differences found

\section{RESULTS}

Table 1 shows the proportion of the children who had used different services during the preceding three months, and the proportion who had been in hospital the previous year, by age group, sex, country, and degree of urbanisation. The youngest of the three age groups used most services, while there was little difference between the other age groups. Gender differences were small. The physician services, especially specialist services, were used less in rural areas. Icelandic children used most services and Swedish children fewest, surpassed only by Norwegian children-for specialist services.

Table 2 shows in the first column the proportion of children with parents in each socioeconomic group in the Nordic countries as a whole. The remaining part of the table shows the socioeconomic differences in children's use of health services. Socioeconomic differences were more distinct if not adjusted for urbanisation grade (results not shown), obviously because

Table 1 Number and prevalence (\%) of children within each category using different form of health services during the preceding three months

\begin{tabular}{|c|c|c|c|c|c|c|c|c|}
\hline & \multicolumn{2}{|l|}{ GP } & \multicolumn{2}{|c|}{ Phone call } & \multicolumn{2}{|c|}{ Specialist } & \multicolumn{2}{|c|}{ Hospital } \\
\hline & $\mathrm{N}$ & $\%$ & $N$ & $\%$ & $\mathrm{~N}$ & $\%$ & $\mathrm{~N}$ & $\%$ \\
\hline Overall & 2325 & 22.5 & 2348 & 23.8 & 1640 & 15.9 & 658 & 6.4 \\
\hline \multicolumn{9}{|l|}{ By sex } \\
\hline Boy & 1148 & 22.0 & 1157 & 22.9 & 833 & 15.9 & 361 & 5.9 \\
\hline Girl & 1140 & 23.0 & 1169 & 24.7 & 790 & 16.0 & 283 & 5.7 \\
\hline \multicolumn{9}{|l|}{ By age group } \\
\hline Age $2-6$ & 967 & 28.8 & 1127 & 35.3 & 644 & 19.2 & 280 & 8.5 \\
\hline Age 7-12 & 715 & 18.8 & 669 & 18.4 & 568 & 14.9 & 185 & 4.9 \\
\hline Age $13-17$ & 611 & 20.2 & 522 & 18.1 & 414 & 13.6 & 183 & 6.2 \\
\hline \multicolumn{9}{|l|}{ By country } \\
\hline Sweden & 351 & 16.5 & 340 & 16.0 & 295 & 13.8 & 117 & 5.5 \\
\hline Iceland & 614 & 30.0 & 562 & 28.5 & 462 & 22.6 & 137 & 6.9 \\
\hline Norway & 454 & 23.0 & 456 & 25.8 & 238 & 12.3 & 122 & 6.4 \\
\hline Finland & 497 & 34.4 & 347 & 18.6 & 305 & 15.0 & 154 & 7.8 \\
\hline Denmark & 409 & 18.9 & 643 & 30.5 & 340 & 15.7 & 128 & 6.0 \\
\hline \multicolumn{9}{|l|}{ By urban grade } \\
\hline Town $>100000$ inhabitants & 790 & 24.8 & 822 & 26.7 & 637 & 20.0 & 187 & 5.9 \\
\hline Town/village 3000-100000 & 830 & 22.1 & 838 & 23.5 & 532 & 14.2 & 246 & 6.7 \\
\hline Rural area $<3000$ inhabitants & 647 & 21.0 & 657 & 21.0 & 450 & 14.0 & 211 & 6.7 \\
\hline
\end{tabular}


Table 2 Socioeconomic differences in use of health care among children in the Nordic countries as a whole. Odds ratios with the highest group as a reference

\begin{tabular}{|c|c|c|c|c|c|c|c|c|c|c|c|c|c|}
\hline \multirow[b]{3}{*}{ Model } & \multirow{3}{*}{$\begin{array}{l}\% \text { of } \\
\text { children }\end{array}$} & \multicolumn{12}{|c|}{ Odds ratios } \\
\hline & & \multicolumn{3}{|l|}{ GP } & \multicolumn{3}{|c|}{ Phone call } & \multicolumn{3}{|c|}{ Specialist } & \multicolumn{3}{|l|}{ Hospital } \\
\hline & & 1 & II & III & 1 & II & III & 1 & II & III & 1 & II & III \\
\hline \multicolumn{14}{|l|}{ Mother's education } \\
\hline University/college & 29.8 & 1.00 & 1.00 & 1.00 & 1.00 & 1.00 & 1.00 & 1.00 & 1.00 & 1.00 & 1.00 & 1.00 & 1.00 \\
\hline $\begin{array}{l}\text { Secondary school } \\
\text { (>12 years) }\end{array}$ & 25.0 & 1.09 & 1.06 & 1.03 & 0.92 & $0.86^{*}$ & 0.89 & 0.94 & 0.90 & 0.91 & $1.62 * * *$ & $1.57 * * *$ & $=1.58 * *$ \\
\hline $\begin{array}{l}\text { Secondary school } \\
\text { (10-12 years) }\end{array}$ & 27.4 & 1.13 & 1.09 & 1.04 & $0.85^{*}$ & $0.80 * *$ & 0.86 & 0.99 & 0.90 & 0.88 & 1.54 *** & $1.40 *$ & $1.37 *$ \\
\hline Primary school & $\begin{array}{l}17.8 \\
100.0\end{array}$ & 0.97 & 0.92 & 0.86 & $0.83^{*}$ & $0.71 * * *$ & $0.73^{* *}$ & $0.72 *$ & $0.64 * * *$ & $0.68^{* *}$ & $1.86 * * *$ & $1.70 * * *$ & $1.66 * *$ \\
\hline \multicolumn{14}{|l|}{ Father's education } \\
\hline University/college & 29.7 & 1.00 & 1.00 & 1.00 & 1.00 & 1.00 & 1.00 & 1.00 & 1.00 & 1.00 & 1.00 & 1.00 & 1.00 \\
\hline $\begin{array}{l}\text { Secondary school } \\
\text { (>12 years) } \\
\text { Secondary school }\end{array}$ & 23.9 & 1.07 & 1.03 & 1.01 & 0.93 & $0.84^{*}$ & 0.86 & 0.95 & 0.91 & 0.99 & $1.40^{*}$ & $1.34^{*}$ & 1.14 \\
\hline (10-12 years) & 25.2 & 1.04 & 1.03 & 1.04 & 0.80 ** & $0.74 * * *$ & 0.81 * & 0.87 & $0.80 *$ & 0.90 & 1.28 & 1.25 & 1.03 \\
\hline Primary school & $\begin{array}{l}21.2 \\
100.0\end{array}$ & 1.06 & 1.02 & 1.07 & $0.81^{* *}$ & $0.75^{* * *}$ & 0.83 & 0.88 & $0.81 *$ & 1.04 & $1.46^{*}$ & $1.48 * *$ & 1.19 \\
\hline \multicolumn{14}{|c|}{ Disposable family income } \\
\hline $\begin{array}{l}\text { Highest quartile } \\
\text { Second highest }\end{array}$ & 25.3 & 1.00 & 1.00 & 1.00 & 1.00 & 1.00 & 1.00 & 1.00 & 1.00 & 1.00 & 1.00 & 1.00 & 1.00 \\
\hline quartile & 27.1 & 1.00 & 1.08 & 1.06 & 0.92 & 0.92 & 0.99 & 0.99 & 0.98 & 1.01 & 0.97 & 0.93 & 0.85 \\
\hline Third highest quartile & 23.0 & 1.06 & 1.06 & 1.02 & 0.89 & 0.86 & 0.95 & 0.89 & 0.85 & 0.91 & 1.17 & 1.17 & 1.02 \\
\hline Lowest quartile & $\begin{array}{l}24.6 \\
100.0\end{array}$ & 1.07 & 1.04 & 1.00 & 1.07 & 0.97 & 1.01 & 0.91 & $0.77 * *$ & 0.85 & $1.32 *$ & $1.32 *$ & 1.00 \\
\hline
\end{tabular}

${ }^{*} p<0.05,{ }^{* *} p<0.01,{ }^{* *} p<0.001$. Model I: adjusted for age, sex, and urbanisation grade. Model II: additionally adjusted for health. Model III: as model II but additionally adjusted for other SES in the table.

people in higher socioeconomic classes more often live in urban areas, where use is higher (table 1).

In the Nordic countries as a whole the use of GP services was similar in different socioeconomic groups. The exception was a lesser use of GP services by children who have mothers with only primary school education, but the difference is not statistically significant.

There were considerable socioeconomic differences in the use of phone calls to doctors according to educational level of the parents. The lower the education of the parents the lower was the use of telephone consultations with doctors. This association was stronger in the case of mother's education, as seen in model III where other factors have been adjusted for. There was no association between phone calls and income of the family.

Children who had parents with lower education and income used less specialist services than children did in higher socioeconomic groups. The difference between the highest and the lowest category was statistically significant for all three socioeconomic variables (model II). Here again the mother's education stands out as the most important socioeconomic factor after adjusting for the other two socioeconomic variables (model III).

Hospital services for children showed quite an opposite picture, with higher odds ratios in the lower socioeconomic groups in model I and II. The results were statistically significant for the lower educational categories of the parents and especially for the mother.

Table 3 shows the socioeconomic differences in the use of physician services in each of the Nordic countries after adjustment for health, age, sex, and urbanisation grade. In most countries the same picture was seen as the one discussed above, but with some exceptions. In Denmark the GP services were less used by children with parents with lower education and income. In Finland GP services were used significantly more often by the lowest income group. Phone calls were generally used less by the lower classes in all countries except in Sweden. Specialist services were also generally less used by the lower classes in all countries, but the difference was less marked in Sweden and Iceland. Hospital services were more used by the lower socioeconomic groups in all countries with the exception of the lowest income groups in Iceland and Sweden. The positive association of hospital use with educational level of the parents was most pronounced in Denmark.

\section{DISCUSSION}

The main findings of this paper are that there were little differences according to SES in the use of GP services in the Nordic countries as a whole, that phone calls to doctors and use of specialist services were significantly less used by lower class children, but lower class children were more often admitted to hospital. The use of services had stronger associations with the parent's education, especially the mother's education, than with the family income. Similar associations were observed between for each country separately with a few exceptions. In general, differential use was more marked in Denmark, Finland and Norway than in Sweden and Iceland.

The question may be raised whether the results are biased attributable to non-response. It was observed that nonresponse was higher in lower socioeconomic groups (see Methods). This higher non-response may have underestimated the use of the services by children in lower groups (and of inequalities in their health care use) if non-response among parents is related to higher health care use of their children. Even though there might perhaps be such an association, there is no reason to expect this relation to be strong. Therefore we would not expect a substantial effect of non-response on the observed inequalities in health care use.

The accuracy of parent reports is assumed to depend on recency and seriousness of an event. Pless and Pless ${ }^{12}$ studied the accuracy of parent recall compared with paediatrician records and found it to be unrelated to demographics such as respondent's age and education. Other studies on parent recall according to SES in surveys of health care use of children support this finding. ${ }^{13} 14$

Adjusting for chronic diseases and symptoms had rather small effects. Children in low socioeconomic groups in the Nordic countries do have more chronic health problems than those in higher socioeconomic groups. ${ }^{15}$ Chronic diseases are 


\begin{tabular}{|c|c|c|c|c|c|c|}
\hline & \multicolumn{2}{|c|}{$\begin{array}{l}\text { Mother only primary } \\
\text { school }\end{array}$} & \multicolumn{2}{|c|}{$\begin{array}{l}\text { Father only primary } \\
\text { school }\end{array}$} & \multicolumn{2}{|c|}{$\begin{array}{l}\text { Lowest income } \\
\text { quartile }\end{array}$} \\
\hline & OR & $95 \% \mathrm{Cl}$ & OR & $95 \% \mathrm{Cl}$ & OR & $95 \% \mathrm{Cl}$ \\
\hline \multicolumn{7}{|c|}{ General practitioner } \\
\hline Sweden & 0.90 & 0.62 to 1.29 & 1.20 & 0.83 to 1.73 & 1.08 & 0.75 to 1.55 \\
\hline Iceland & 0.95 & 0.67 to 1.34 & 0.88 & 0.91 to 1.28 & 0.96 & 0.69 to 1.33 \\
\hline Norway & 0.79 & 0.54 to 1.16 & 1.12 & 0.78 to 1.62 & 1.02 & 0.73 to 1.45 \\
\hline Finland & 0.91 & 0.62 to 1.33 & 1.03 & 0.69 to 1.54 & 1.54 & 1.01 to 2.16 \\
\hline Denmark & 0.63 & 0.39 to 1.02 & 0.88 & 0.61 to 1.27 & 0.75 & 0.53 to 1.07 \\
\hline \multicolumn{7}{|l|}{ Phone call } \\
\hline Sweden & 0.92 & 0.65 to 1.32 & 1.26 & 0.87 to 1.81 & 1.04 & 0.73 to 1.49 \\
\hline Iceland & 0.75 & 0.52 to 1.10 & 0.66 & 0.44 to 1.99 & 0.86 & 0.61 to 1.23 \\
\hline Norway & 0.75 & 0.52 to 1.12 & 0.72 & 0.49 to 1.07 & 0.89 & 0.63 to 1.27 \\
\hline Finland & 0.78 & 0.50 to 1.21 & 0.74 & 0.47 to 1.18 & 0.99 & 0.67 to 1.44 \\
\hline Denmark & 0.81 & 0.53 to 1.24 & 0.99 & 0.71 to 1.39 & 1.08 & 0.78 to 1.50 \\
\hline \multicolumn{7}{|l|}{ Specialist } \\
\hline Sweden & 0.77 & 0.52 to 1.14 & 1.10 & 0.75 to 1.62 & 0.83 & 0.56 to 1.24 \\
\hline Iceland & 0.88 & 0.60 to 1.28 & 0.80 & 0.54 to 1.18 & 0.84 & 0.59 to 1.20 \\
\hline Norway & 0.51 & 0.30 to 0.85 & 0.76 & 0.47 to 1.21 & 0.64 & 0.41 to 1.02 \\
\hline Finland & 0.34 & 0.21 to 0.55 & 0.63 & 0.40 to 0.99 & 0.56 & 0.38 to 0.84 \\
\hline Denmark & 0.52 & 0.29 to 0.91 & 0.62 & 0.40 to 0.97 & 0.91 & 0.62 to 1.33 \\
\hline \multicolumn{7}{|l|}{ Hospital } \\
\hline Sweden & 1.78 & 0.98 to 3.23 & 1.58 & 0.88 to 2.83 & 0.81 & 0.44 to 1.50 \\
\hline Iceland & 1.19 & 0.64 to 2.21 & 1.08 & 0.55 to 2.12 & 0.91 & 0.52 to 1.60 \\
\hline Norway & 1.92 & 1.04 to 3.57 & 1.04 & 0.52 to 2.07 & 1.39 & 0.75 to 2.59 \\
\hline Finland & 1.39 & 0.67 to 2.91 & 1.37 & 0.66 to 2.83 & 1.55 & 0.87 to 2.66 \\
\hline Denmark & 2.22 & 1.15 to 4.33 & 2.02 & 1.12 to 3.64 & 1.21 & 0.68 to 2.17 \\
\hline
\end{tabular}

not as common among children as they are among adults and physicians see children more often for acute diseases. The expected need of the children can only be partially controlled for in this study, as no information on recent acute diseases was available. It may be expected that, if control could have been made for more accurate measures of need, we would have observed larger inequities in health care utilisation.

These findings, especially with regard to the specialist services, give reasons to ask whether the co-payment in the Nordic countries ${ }^{16}$ acts as a barrier for the use of the services by parents in the lower income groups. In Denmark both GP and specialist services were free at the point of use in 1996. In Finland there was no charge for persons under 15 at the health care centres. In Norway treatment for children under age 7 was free of charge but other children paid \$18 for a GP and \$25 for a specialist consultation. Icelandic children paid a reduced fee of $\$ 3$ for a GP consultation and $\$ 7$ for a specialist. The highest co-payment was in Sweden: the local authorities set the charges and they varied between $\$ 10$ and $\$ 20$ for a GP and between $\$ 25$ and $\$ 45$ for a specialist for children at any age.

In Sweden there is concern about rising co-payment in outpatient care. The Level of Living Survey in 1993-4, conducted on a regular basis in Sweden, showed for the first time in many years that there was a statistically increasing difference between educational groups in the use of outpatient health care for adults, adjusted for health status. This was referred to as "cracks in the welfare wall". ${ }^{17}$ However, no differences were found in the use of health services for children between income groups. Other studies ${ }^{18}$ indicate that people refrained from consulting a doctor because of cost and, as could be expected, this was more common among people in low income groups. These results have been challenged because of the risk of tactic answers and lack of answer alternatives regarding reasons for not visiting a doctor. ${ }^{19}$

Denmark is of special interest as there is no co-payment for the services and as only in Denmark the GP acted as gatekeepers to the specialist services, even though people in all of these countries were expected to contact their GP in the first hand. Denmark showed larger differences than Sweden in use of GP services according to family income, but both countries had similar low levels of differential use of specialist services according to family income. If co-payment were a barrier we would expect larger inequalities in the countries with higher co-payment, especially when comparing Denmark with Sweden on the opposite ends of the co-payment spectrum and with the same response rate. No such relation was found.

In general there were differences in the use of specialists according to the educational levels of the parents, especially the mother's education. This indicates that better educated parents are more able to go directly to a specialist, to by pass the gatekeeper function of the GP or negotiate for referral to a specialist. This difference was not smaller in Denmark with its referral system to specialist care than in most of the other countries. Mother's education may determine health care use in several ways, including the suggestion of earlier research that the more educated mother is more likely to interpret her own child's symptoms as abnormal, while still being able to discriminate their relative severity. ${ }^{20}$ If the same applies to this study, underutilisation of health services by low educated mothers is a more probable explanation than overuse by the more educated.

\section{CONCLUSION}

The specialist services and use of telephone services for children in the Nordic countries do not meet the criteria of equal use for equal need whereas the GP services and hospital services do to some extent. The comparison between countries shows no relation between different levels of co-payment and differential use of physician services by income groups. Low education of parents, especially the mother, is a more important determinant of health care utilisation for children than the financial situation of the families in the Nordic countries. The finding that telephone services for children in lower classes, with very low direct costs, are not used to the same degree for children of better educated parents also supports this. 


\section{ACKNOWLEDGEMENTS}

The study Health and Well-being of Children and Young People in the Nordic countries 1996 was conducted by the Nordic School of Public Health in Gothenburg with financial support from the Joint Committee of the Nordic Social Science Research Councils. This part was financially supported by the Icelandic Research Council (Rannis) and Save the Children Iceland (Barnaheill).

\section{Authors' affiliations}

$M$ Halldórsson, Directorate of Health in Iceland

A E Kunst, J P Mackenbach, Department of Public Health, Erasmus University, Rotterdam, the Netherlands

L Köhler, Nordic School of Public Health, Gothenburg, Sweden

\section{REFERENCES}

1 Townsend P, Davidson N. Inequalities in health. The Black report. London: Penguin, 1982.

2 Saxena S, MajeedA, Jones M. Socioeconomic differences in childhood consultation rates in general practice in England and Wales: prospective cohort study. BM 1999;318:642-6.

3 Fernandez de la Hoz K, Leon DA. Self perceived health status and inequalities in use of health services in Spain. Int J Epidemiol 1996;25:593-606.

4 Peterson C, Hakanson A. High-consulting children indicate illness-prone families. A study of 38 rural and 38 urban Swedish children's health and use of medical care. Scand J Prim Health Care 1996;14:71-7.

5 Bruijnzeels MA, Wouden JC van der, Foets M. General practice consultation in childhood in The Netherlands: sociodemographic variation. J. Epidemiol Community Health 1995:49:532-3.

6 Cooper H, Smaje C, Arber S. Use of health services by children and young people according to ethnicity and social class: secondary analysis of a national survey. BM 1998;317:1047-51.
7 Newacheck PW, Hughes DC, Stoddard JJ. Children's access to primary care: differences by race, income and insurance status. Pediatrics 1996;97:26-32.

8 Flores G, Bauchner $\mathrm{H}$, Feinstein AR, et al. The impact of ethnicity, family income, and parental education on children's health and use of health services. Am J Public Health 1999;89:1066-71.

9 Kephart G, Thomas VS, MacLean DR. Socioeconomic differences in the use of physician services in Nova Scotia. Am J Public Health 1998; 88:800-3.

10 Taylor J. Access to health care for children in low-income families. Aust J Public Health 1994; 18:111-13.

11 Berntsson LT, Köhler L. Long-term illness and psychosomatic complaints in children aged 2-17 years in the five Nordic Countries. Comparison between 1984 and 1996. Eur J Public Health 2001;11:35-42.

12 Pless CE, Pless IB. How well they remember: The accuracy of parents' reports. Arch Pediatr Adolesc Med 1955;149:553-8.

13 Rajmil L, Fernandez E, Gispert R, et al. Influence of proxy respondents in children's health interview surveys. J Epidemiol Community Health 1999;53:38-42.

14 Suarez L, Simpson DM, Smith DR. Errors and correlates in parental recall of child immunisations: effects on vaccination coverage estimates. Pediatrics 1997;99:E3.

15 Halldorsson $\mathbf{M}$, Kunst $A E$, Köhler L, et al. Socioeconomic inequalities in the health of children and adolescents: a comparative study of the five Nordic countries. Eur J Public Health 2000; 10:281-8.

16 Health statistics for the Nordic countries 1995. Copenhagen: NOMESCO, 1997

17 Haglund B, Rosèn M. Sprickor i välfardsmuren. Lågutbildade missgynnas. Läkartidningen 1996;93:3672-7.

18 Elofsson S, Undén A-L, Krakau I. Patientavgifter. Ett hinder att söka vård. Stockholm: Allmänmedicinska enheten NVSO, 1997.

19 Sweden's Public Health Report 1997. Stockholm: Epidemiologiskt Centrum-Socialstyrelsen, 1998.

20 Stine OC, Chuaqui C. Mothers' intended actions for childhood symptoms. Am J Public Health 1969;59:2035-45.

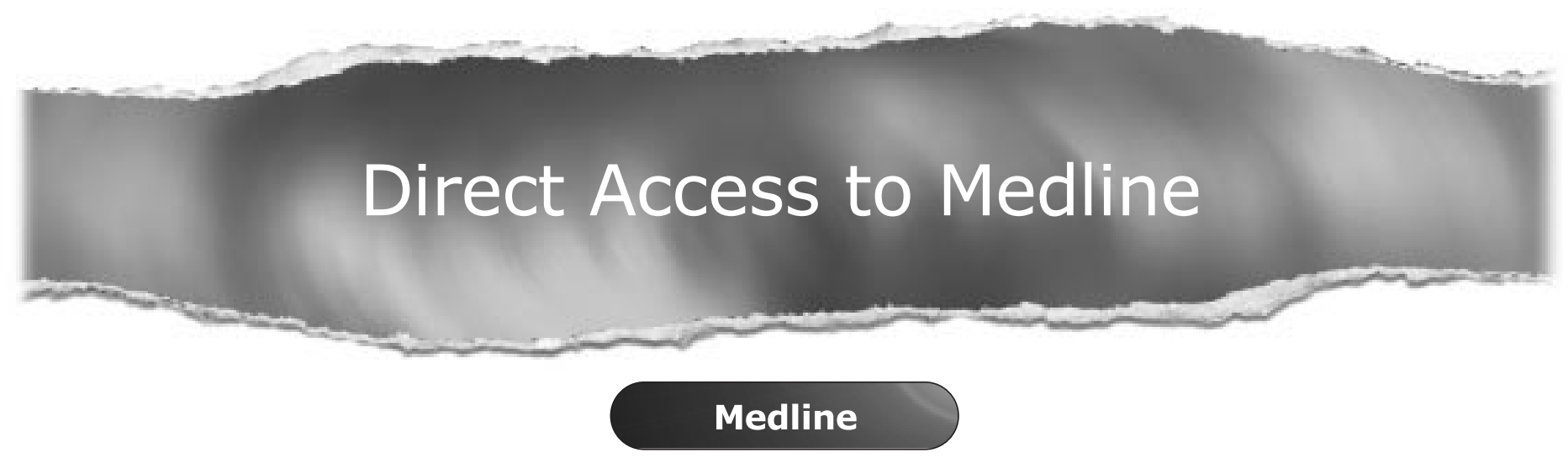

Link to Medline from the homepage and get straight into the National Library of Medicine's premier bibliographic database. Medline allows you to search across 9 million records of bibliographic citations and author abstracts from approximately 3,900 current biomedical journals.

\section{www.jech.com}

